\title{
ANALISIS KUALITAS PELAYANAN TERHADAP KEPUASAN PASIEN DI PUSKESMAS X KOTA JAMBI
}

\section{Quality Analysis Of Service To Patient Satisfaction In X Community Health Center, Jambi City}

\author{
Merry Christiani Nababan ${ }^{1}$, Renny Listiawaty ${ }^{1}$, Novi Berliana ${ }^{1}$
}

${ }^{1}$ Program Studi Kesehatan Masyarakat, STIKES Harapan Ibu Jambi

\begin{abstract}
Abstrak
Kualitas pelayanan kesehatan sangat berhubungan erat dengan kepuasan. Penelitian ini bertujuan untuk mengetahui tingkat kepuasan dan analisis (harapan dan kenyataan) kualitas pelayanan kesehatan di Puskesmas X Kota Jambi Tahun 2020. Penelitian ini merupakan penelitian deskriptif. Sampel penelitian berjumlah 96 orang. metode pengambilan sampel dengan accidental sampling. Penelitian dilakukan pada tanggal 3 Februari sampai dengan tanggal 8 Februari. Instrument penelitian ini menggunakan kuesioner. Analisis data yang digunakan adalah analisis univariat dan analisis Importance Performance Analysis (IPA) yakni dengan menggunakan Diagram Kartesius. Hasil penelitian diketahui tingkat kesesuain anatara kenyataan dan harapan berdasarkan lima dimensi mutu pada dimensi Kehandalan (Reliability) 97,3 \%, dimensi Daya Tanggap (Responsiveness) 95,75 \%, dimensi Jaminan (Assurance) 95,06 \%, dimensi Empati (Emphaty) $93.18 \%$ dan dimensi Bukti Fisik (Tangible) 95,94 \%. Berdasarkan hasil studi disarankan agar melakukan evaluasi secara rutin setiap 6 bulan, perbaikan dengan memberikan pelatihan dan kerjasama dengan petugas dalam peningkatan kualitas pelayanan yang berfokus pada kepuasan pasien.
\end{abstract}

Kata Kunci: Kepuasan, Dimensi Mutu

\begin{abstract}
The quality of health services is very closely related to satisfaction. This study aims to determine the level of satisfaction and analysis (expectations and reality) of the quality of health services at the $\mathrm{X}$ Health Center in Jambi City in 2020. This research is a descriptive study. The research sample amounted to 96 people. sampling method with accidental sampling. The study was conducted on February 3 through February 8. The research instrument used a questionnaire. Analysis of the data used is univariate analysis and Importance Performance Analysis (IPA) analysis using Cartesian Diagrams. The results of the study are known to be the level of conformity between reality and expectations based on five quality dimensions on the reliability dimension $97.3 \%$, the responsiveness dimension $95.75 \%$, the assurance dimension $95.06 \%$, the empathy dimension $93.18 \%$ and the physical proof dimension $95.94 \%$. Based on the results of the study it is recommended that regular evaluations be conducted every 6 months, improvement by providing training and collaboration with officers in improving the quality of services that focus on patient satisfaction.
\end{abstract}

Keywords: Satisfaction, Quality Dimensions

Korespondensi : Merry Christiani Nababan

Email : christianimery37@yahoo.com

\section{PENDAHULUAN}

Kepuasan pasien didefinisikan sebagai respon pelanggan terhadap ketidaksesuaian antara tingkat kepentingan sebelumnya dan kinerja aktual yang dirasakannya setelah pemakaian. Kepuasan pasien/pelanggan adalah inti dari pemasaran yang berorientasi kepada pasien/pelanggan. Pelayanan yang memuaskan dan berkualitas akan 
membentuk loyalitas pasien/pelanggan dan kepuasan. maka pelayanan yang memuaskan tersebut juga akan mendatangkan pelanggan baru. Efek selanjutnya akan berlanjut pada proses terbentuknya citra puskesmas yang meningkat. Hal ini dikarenakan kondisi persaingan yang sangat ketat. Maka setiap puskesmas akan berusaha untuk menempatkan dirinya sebaik mungkin dimata pasien/pelanggannya agar dapat dipercaya untuk memenuhi kebutuhannya dalam bidang kesehatan (1).

Kualitas pelayanan kesehatan sangat berhubungan erat dengan kepuasan. Penelitian yang dilakukan oleh Sri (2016) di Solo Dari kelima aspek dimensi kualitas yang dinilai untuk mengetahui tingkat kepuasan pasien terhadap pelayanan kesehatan (rawat jalan) di Puskesmas Baturetno menunjukkan bahwa pasien merasa puas dengan membandingkan harapan dan pengalaman yang menggambarkan tingkat kepuasan pasien terhadap pelayanan kesehatan dalam 5 dimensi kualitas pelayanan. Tingkat kepuasan secara keseluruhan dikategorikan puas (2). Hasil Penelitian Wahyu (2017) di Yogyakarta tentang kepuasaan pasien terhadap kualitas pelayanan di tempat pendaftaran pasien rawat jalan Puskemas Kretek menyatakan bahwa Distribusi kepuasan secara menyeluruh mayoritas pada kategori puas. Dilihat dari setiap dimensi masih ada kategori tidak puas pada dimensi assurance khususnya item pasien yakin akan kemampuan petugas. Selain itu tidak ada perbedaan kepuasan berdasarkan karakteristik Jenis Kelamin, Usia, dan Pekerjaan. Namun ada perbedaan kepuasan yang bermakna pada karakteristik pendidikan (3).

Beberapa hasil penelitian menunjukan data tentang tingkat kepuasan pasien di berbagai Negara. Tingkat kepuasan pasien menurut Ndambuki tahun 2013 di Kenya menyatakan 40,4\%, kepuasan pasien di Bakhtapur India menurut Twayana 34,4\% (4)., sedangkan di Indonesia menunjukkan angka kepuasaan pasien $42,8 \%$ di Maluku Tengah dan 44,4\% di Sumatra Barat ((5) (6)). Berdasarkan data tersebut dapat disimpulkan bahwa angka kepuasaan pasien masih tergolong rendah, sehingga kepuasaan pasien menjadi permasalahan baik di Indonesia maupun di luar negeri.

Penelitian Dzomeku (2013), pasien laki-laki sebesar $38 \%$ puas terhadap pelayanan dan perempuan sebesar $30 \%$ (7). Penelitian Ardiansyah (2015) menunjukkan data $56,1 \%$ pasien yang bekerja menyatakan puas dibandingkan pasien yang tidak bekerja $76,5 \%$ pasien menyatakan puas (8).

Puskesmas X Kota Jambi sebagai salah satu unit pelayanan teknis dinas kesehatan kota jambi dituntut menjadi ujung tombak pembangunan kesehatan khususnya memberikan pelayanan kesehatan kepada masyarakat yang bersifat promotif, kuratif tanpa mengabaikan pelayanan yang bersifat preventif dan rehabilitative untuk mempertinggi derajat kesehatan dengan memberikan prioritas pada upaya peningkatan kesehatan di wilayah kerja puskesmas X, pelayanan kesehatan ini tertuang dalam 6 program pokok dan program pengembangan puskesmas antara lain Promosi kesehatan, Kesehatan lingkungan, Kesehatan ibu dan anak, Keluarga berencana, Perbaikan gizi masyarakat dan Pencegahan dan pemberantasan penyakit menular dan upaya pengobatan.

Data Puskesmas X diketahui jumlah kunjungan pasien di Puskesmas X Kota Jambi per tahun mengalami fluktuasi. 
Jumlah kunjungan pasien yang paling tertinggi pada tahun 2017 sebanyak 74.647 kunjungan, sedangkan pada tahun 2014 kunjungan pelayanan puskesmas mengalami penurunan sebanyak 61.489 kunjungan. Namun demikian terjadi penurunan kunjungan pelayanan kesehatan dalam 1 tahun terakhir yaitu pada tahun 2018 sebanyak 69.215 kunjungan

Data Survey Kepuasan Masyarakat (SKM) di Puskesmas X semester I tahun 2019, diketahui 2 unsur pelayanan yang belum mencapai rata-rata tertimbang dengan nilai 3,26 adalah unsur pelayanan persyaratan dan penanganan, pengaduan, saran dan masukan. Nilai unsur pelayanan yaitu 3,21. Data dari kotak saran di Puskesmas X Tahun 2019, berisi keluhan berkaitan tentang respon pelayanan dan pemahaman informasi yang diberikan oleh petugas kepada pengunjung yang menggunakan pelayanan kesehatan di Puskesmas X Kota Jambi.

Penelitian ini bertujuan untuk mengetahui gambaran kualitas pelayanan terhadap kepuasan pasien di Puskesmas X Kota Jambi.

\section{METODE}

Penelitian ini merupakan penelitian deskriptif kuantitatif dengan yang bertujuan untuk mengetahui analisis kualitas pelayanan terhadap kepuasan pasien di Puskesmas X Kota Jambi Tahun 2020. Populasi dalam penelitian ini adalah seluruh pasien yang menggunakan pelayanan kesehatan di Puskesmas X Kota Jambi Tahun 2019 yang berjumlah 14.882 kunjungan. Pengambilan sampel dalam penelitian ini menggunakan accidental sampling dengan jumlah sampel sebanyak 96 sampel. Pengumpulan data dilakukan pada tanggal 3 Februari sampai dengan 8 Februari Tahun 2020. Analisis data yang digunakan adalah analisis univariat dan analisis Importance Performance Analysis (IPA) yakni dengan menggunakan Diagram Kartesius. Metode pengumpulan data adalah dengan wawancara menggunakan kuesioner.

\section{HASIL PENELITIAN}

Penelitian ini menemukan bahwa tingkat kepuasan pasien berdasarkan dimensi kehandalan (reliability) sebesar $97,73 \%$, dimensi kehandalan daya tanggap (responsiveness) sebesar 95,75\%, dimensi jaminan (assurance) sebesar 95,06\%, dimensi empati (emphaty) sebesar 93,18\%, dimensi buti fisik (tangible) sebesar 95,94\% (Tabel 1).

Hasil analisa menggunakan diagram kartesius, faktor-faktor yang menjadi prioritas perbaikan (Kuadran A) dan harus dilaksanakan sesuai dengan harapan pelanggan adalah Prosedur Pelayanan tidak berbelit-belit dan Pengetahuan dan kemampuan tenaga medis menetapkan diagnosis penyakit (diagram 1). 
Tabel 1. Tingkat Kepuasan Pasien berdasarkan Kesesuaian antara Kenyataan dan Harapan di Puskesmas X Kota Jambi

\begin{tabular}{llccc}
\hline No & \multicolumn{1}{c}{ Dimensi } & Kenyataan & Harapan & Tingkat Kepuasan \\
\hline 1 & Kehandalan & 1512 & 1547 & 97,73 \\
\hline 2 & Ketanggapan & 1104 & 1153 & 95,75 \\
\hline 3 & Jaminan & 1465 & 1541 & 95,06 \\
\hline 4 & Empati & 1015 & 1101 & 93,18 \\
\hline 5 & Bukti Fisik & 1489 & 1552 & 95,94 \\
\hline & Total & 6585 & 6894 & 95,52 \\
\hline
\end{tabular}

Sebelum mendapatkan diagram kartesius maka peneliti mencari kesesuaian antara kenyataan dan harapan dari 18 atribut hasilnya sebagai berikut :

Tabel 2. Data Perbandingan antara Kenyataan dan Harapan pada Atribut Dimensi Mutu Pelayanan

\begin{tabular}{|c|c|c|c|c|c|}
\hline No & Dimensi mutu & No & $\begin{array}{c}\text { Rerata } \\
\text { Harapan (Y) }\end{array}$ & $\begin{array}{c}\text { Rerata } \\
\text { Kenyataan }(\mathrm{X})\end{array}$ & $\begin{array}{c}\text { Tingkat } \\
\text { Kesesuaian }\end{array}$ \\
\hline \multirow[t]{4}{*}{1} & \multirow{4}{*}{$\begin{array}{r}\text { A. Kehandalan } \\
\text { (Reliability) }\end{array}$} & A1 & 4,08 & 3,93 & $96,32 \%$ \\
\hline & & $\mathrm{A} 2$ & 4,02 & 3,96 & $98,50 \%$ \\
\hline & & A3 & 4,04 & 3,92 & $97,02 \%$ \\
\hline & & A4 & 3,96 & 3,91 & $98,73 \%$ \\
\hline \multirow[t]{3}{*}{2} & \multirow{3}{*}{$\begin{array}{l}\text { B. Daya Tanggap } \\
\text { (Responsivenes) }\end{array}$} & B1 & 3,91 & 3,79 & $96,93 \%$ \\
\hline & & B2 & 4,11 & 4,01 & $97,56 \%$ \\
\hline & & B3 & 3,97 & 3,69 & $92,94 \%$ \\
\hline \multirow[t]{4}{*}{3} & \multirow{4}{*}{$\begin{array}{l}\text { C. Jaminan } \\
\text { (Assurance) }\end{array}$} & $\mathrm{C} 1$ & 3,95 & 3,86 & $97,72 \%$ \\
\hline & & $\mathrm{C} 2$ & 3,98 & 3,61 & $90,70 \%$ \\
\hline & & $\mathrm{C} 3$ & 4,15 & 3,98 & $95,90 \%$ \\
\hline & & $\mathrm{C} 4$ & 3,94 & 3,79 & $96,19 \%$ \\
\hline \multirow[t]{3}{*}{4} & \multirow{3}{*}{$\begin{array}{l}\text { D. Empati } \\
\text { (Emphaty) }\end{array}$} & D1 & 3,71 & 3,43 & $92,45 \%$ \\
\hline & & D2 & 3,81 & 3,47 & $91,07 \%$ \\
\hline & & D3 & 3,93 & 3,65 & $92,87 \%$ \\
\hline \multirow[t]{4}{*}{5} & \multirow{4}{*}{$\begin{array}{l}\text { E. Bukti Fisik } \\
(\text { Tangible })\end{array}$} & E1 & 4,05 & 3,90 & $96,29 \%$ \\
\hline & & $\mathrm{E} 2$ & 4,01 & 3,87 & $96,50 \%$ \\
\hline & & E3 & 3,97 & 3,75 & $94,45 \%$ \\
\hline & & E4 & 4,12 & 3,97 & $96,35 \%$ \\
\hline \multicolumn{3}{|c|}{ Rerata Total } & 72,02 & 68,49 & $95,09 \%$ \\
\hline
\end{tabular}




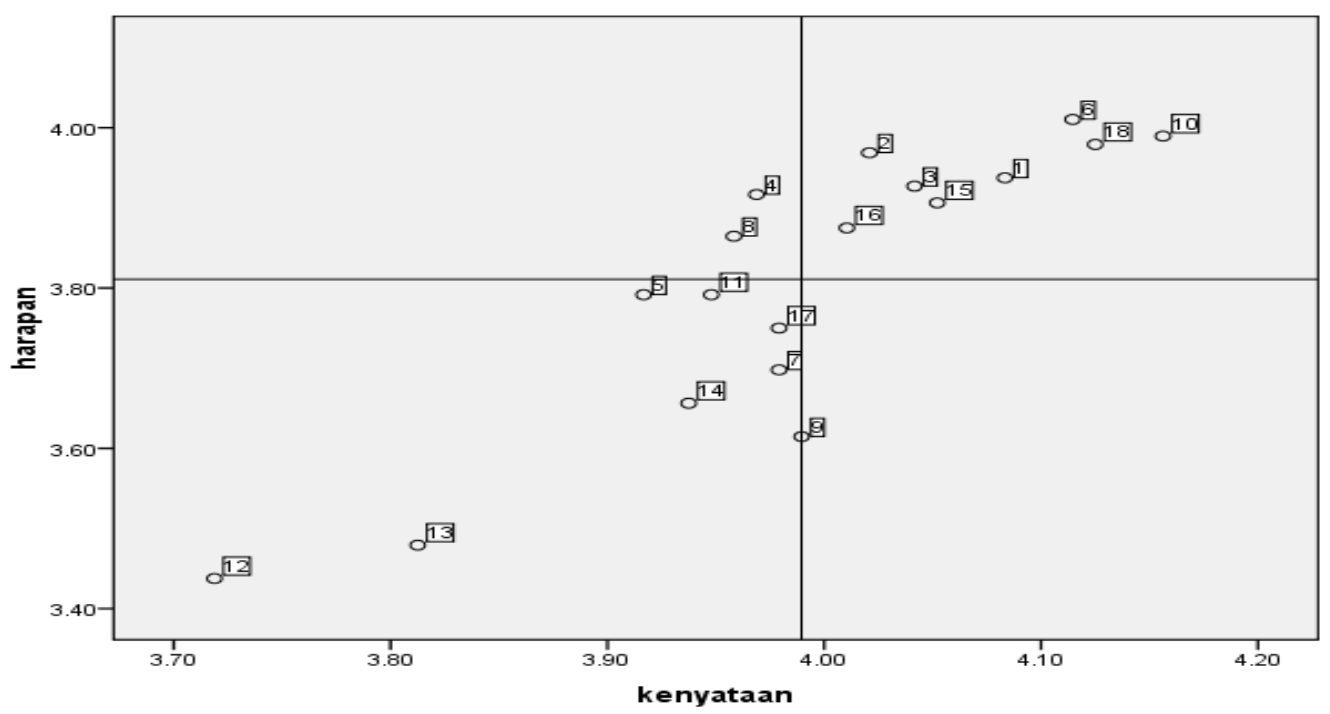

Diagram 1. Diagram Kartesius

Diagram 1 menunjukkan terdapat 4 kuadran yaitu Kuadran A, B, C dan D. Atribut yang masuk masing-masing kuadran sebagai berikut :

1. Kuadran A yakni atributdengan tingkat harapan (kepentingan) yang tinggi, akan tetapi tingkat kenyataan dinilai rendah, sehingga menjadi prioritas utama untuk diperbaiki.

a. A4 = Prosedur Pelayanan tidak berbelit-belit sebesar 98,68\%

b. $\mathrm{C} 8=$ Pengetahuan dan kemampuan tenaga medis menetapkan diagnosis penyakit sebesar $97.63 \%$

2. Kuadran B Menunjukan atribut-atribut tingkat kepentingan dan tingkat kinerja yang sama-sama tinggi sehingga pasien merasakan kepuasan. Hal ini menuntut puskesmas untuk mempertahankan posisinya

a. $\mathrm{A} 1=$ Prosedur penerimaan pasien yang cepat dan tepat sebesar $96,42 \%$

b. $\mathrm{A} 2=$ Pelayanan pemeriksaaan, pengobatan dan perawatan yang cepat dan tepat sebesar $98,70 \%$

c. A3 = Jadwal pelayanan Puskesmas dijalankan dengan tepat waktu sebesar $97,16 \%$ d. B6 = Petugas memberikan informasi yang jelas dan mudah dimengerti sebesar $97,46 \%$

e. $\mathrm{C} 10$ = Pelayanan yang sopan dan ramah sebesar 95,98\%

f. E15= Kebersihan, kerapian dan kenyamanan ruangan sebesar $96,40 \%$

g. E16 = Penataaan eksterior dan interior ruangan sebesar 96,62\%

h. E18 = Kerapian dan Kebersihan Penampilan Petugas sebesar 96,46\%

3. Kuadran $\mathrm{C}$ Menunjukkan atribut-atribut kualitas pelayanan memiliki tingkat kepentingan dan tingkat kinerja yang sama-sama rendah. Atribut kualitas pelayanan pada kuadrat ini dirasakan tidak terlalu penting oleh pasien, puskesmas melakukan biasa-biasa saja sehingga belum perlu memperbaiki (prioritas rendah).

a. B5 = Kemampuan tenaga medis untuk cepat tanggap menyelesaikan keluhan pasien sebesar $96,80 \%$

b. B7 = Tindakan cepat pada saat pasien membutuhkan sebesar 92,93\% 
c. $\mathrm{C} 11$ = Jaminan keamanan pelayanan dan kepercayaan terhadap pelayanan sebesar $96,04 \%$

d. D12 = Memberikan perhatian secara khusus kepada setiap pasien sebesar $92,43 \%$

e. D13 = Perhatian terhadap keluhan pasien dan keluarganya sebesar 99,40\%

f. $\mathrm{E} 17$ = Kelengkapan, kesiapan dan kebersihan alat-alat yang dipakai sebesar $94,24 \%$

4. Kuadran D Menunjukkan atribut-atribut kualitas pelayanan yang memiliki tingkat kepentingan rendah sedangkan tingkat kinerja nya tinggi dalam pelaksanaan atribut ini dirasakan terlalu berlebihan padahal konsumen menganggapnya kurang penting.

a. C9 = Keterampilan seluruh tenaga medis dalam bekerja sebesar 90,04 $\%$

\section{PEMBAHASAN}

Berdasarkan hasil penelitian tingkat kehandalan (reliability) yang masuk dalam Kuadran A (Prioritas Utama) adalah pernyataan no 4 Prosedur Pelayanan tidak berbelit-belit. Dengan presentasi rata-rata tingkat harapan sebesar 3,96 sedangkan rata-rata tingkat kenyataan sebesar 3,91. Masuk Kuadran B pernyataan no 1 Prosedur penerimaan pasien yang cepat dan tepat, pernyataan no 2 Pelayanan pemeriksaaan, pengobatan dan perawatan yang cepat dan tepat dan pernyataan no 3 Jadwal pelayanan Puskesmas dijalankan dengan tepat waktu.

Hasil penelitian Wahyu 2017 tentang Kepuasan Pasien Terhadap Kualitas Pelayanan di Tempat Pendaftaran Pasien Rawat Jalan Puskesmas Kretek Bantul Yogyakarta, Berdasarkan hasil analisa data pada dimensi kehandalan (reliability) dapat disimpulkan bahwa secara umum mayoritas pasien percaya akan keandalan dan keakuratan pelayanan yang diberikan petugas dengan cepat (3). Hasil penelitian ini diperkuat dengan penelitian sebelumnya bahwa ada hubungan yang bermakna antara reliability dengan kepuasan pasien (9)(10)(11)

Menurut peneliti dalam dimensi mutu kehandalan dalam Kuadran A (Prioritas Utama) pada pernyataan no 4 yaitu Prosedur Pelayanan tidak berbelitbelit. Keluhan responden sebagian masih belum memahami alur pendaftaran, selain itu pada saat menunggu antrian poli responden masih harus menunggu karena less pasien yang belum diantar dari loket pendaftaran ke ruangan poli. Maka dari itu diharapkan pihak puskesmas lebih meningkatkan informasi dalam hal pelayanan seperti membuat alur atau bagan pelayanan dalam bentuk banner atau poster yang sesuai dengan standar pelayanan agar mudah dimengerti dan dipahami responden. Selain itu diharapkan peran Dinas Kesehatan Kota Jambi untuk melakukakn suvervisi di puskesmas terkait dengan pelayanan yang sudah dijalankan pihak Puskesmas.

Berdasarkan hasil penelitian tingkat dimensi daya tanggap (responsiveness) yang masuk dalam dalam kuadran B (dipertahankan) adalah pernyataan no 6 Petugas memberikan informasi yang jelas dan mudah dimengerti. Masuk Kuadran C (Prioritas Rendah) dimana atribut kualitas pelayanan memiliki tingkat kepentingan dan tingkat kinerja yang sama-sama rendah. adalah pernyataan no 5 Kemampuan tenaga medis untuk cepat tanggap menyelesaikan keluhan dan pernyataan no 7 Tindakan cepat pada saat pasien membutuhkan 
Hasil penelitian Herman 2019 tentang analisis faktor yang mempengaruhi mutu pelayanan kesehatan terhadap kepuasan pasien di puskesmas pasaman, berdasarkan hasil analisis data pada dimensi daya tanggap (responsiveness) diperoleh nilai secara statistik dengan uji Chi Square yaitu p-value $=0,018$. Ini menunjukkan bahwa ada hubungan antara daya tanggap dengan kepuasan pasien. Daya tanggap dimasukkan kedalam kemampuan petugas kesehatan menolong pelanggan dan kesiapannya melayani sesuai produser dan bisa memenuhi harapan pelanggan. Dimensi ini merupakan penilaian mutu pelayanan yang paling dinamis. Harapan pelanggan terhadap kecepatan pelayanan cenderung meningkat dari waktu ke waktu sejalan dengan kemajuan teknologi dan informasi kesehatanyang dimiliki oleh pelanggan (12). Hasil penelitian ini diperkuat penelitian sebelumnya bahwa kepuasan pasien berhubungan dengan ketanggapan petugas kesehatan dalam memberikan pelayanan (13) (14).

Menurut peneliti dalam dimensi mutu daya tanggap Kuadran $\mathrm{C}$ pernyataan no 5 Kemampuan tenaga medis untuk cepat tanggap menyelesaikan keluhan dan pernyataan no 7 Tindakan cepat pada saat pasien membutuhkan. Responden memiliki presepsi bahwa tenaga medis di puskesmas tidak cepat pada saat pelayanan berlangsung tenaga medis hanya bercengkrama dengan teman-temannya yang ada di dalam ruangan tersebut. Sehingga responden merasa tidak begitu nyaman dan merasa pelayanan sangat tidak cepat Diharapkan Kepala Puskesmas melakukan evaluasi terhadap kinerja Petugas dalam kegiatan rapat atau kegiatan minilok, untuk mengkoordinasi para petugas agar lebih meningkatkan mutu pelayanan. Untuk Kuadran B pernyataan no 6 petugas memberikan informasi yang jelas dan mudah dimengerti, diharapkan atribut pelayanan ini untuk tetap dipertahakan dalam proses pelayanan di Puskesmas.

Berdasarkan hasil penelitian tingkat dimensi jaminan yang masuk dalam dalam kuadran A (Prioritas Utama) adalah pernyataan no 8 Pengetahuan dan kemampuan tenaga medis menetapkan diagnosis penyakit. Dengan presentasi rata-rata tingkat harapan sebesar 3,95 sedangkan rata-rata tingkat kenyataan sebesar 3,86. Kuadran D pada pernyataan no 9 adalah keterampilan seluruh tenaga medis dalam bekerja. Kuadran B (dipertahankan) yaitu pernyataan no 10 pelayanan yang sopan dan ramah. Kuadran C (Prioritas Rendah) pada pernyataan no 11 Jaminan keamanan pelayanan dan kepercayaan terhadap pelayanan.

Hasil penelitian Siti 2017 tentang hubungan mutu pelayanan dengan kepuasan pasien peserta BPJS di Rumah Sakit Umum Yogyakarta, berdasarkan analisis bivariat diperoleh hasil bahwa ada hubungan dimensi mutu jaminan (assurance) dengan kepuasan pasien $(p=0,000)$. Jika jaminan atas kualitas jasa yang diterima atau dirasakan lebih rendah daripada yang diharapkan, maka kualitas pelayanan kesehatan akan dipersepsikan buruk atau tidak memuaskan. Oleh karena itu, baik atau tidaknya kualitas pelayanan tergantung pada kemampuan penyedia pelayanan dalam memenuhi harapan pasien secara konsisten (15).

Menurut peneliti dalam dimensi jaminan pada kuadran A (Prioritas Utama) pada pernyataan no 8 Pengetahuan dan kemampuan tenaga medis menetapkan diagnosis penyakit. Hal ini terkait dengan kepuasan responden dalam pelayanan, 
dimana responden belum cukup puas terhadap pelayanan yang diberikan petugas di puskesmas, terutama dalam hal diagnosis penyakit sehingga responden mencari alternatif opini diagnosis sehingga mengunjungi fasiltas pelayanan kesehatan yang lain. Diharapkan Dinas Kesehatan Kota Jambi melakukan pemantaun terkait tentang Standar kinerja pelayanan bagi para tenaga medis di Puskesmas Putri Ayu Kota Jambi. Pada Kuadran B diharapkan atribut pelayanan ini dapat dipertahankan dengan mengoptimalkan seluruh petugas puskesmas agar tetap memberikan pelayanan yang sopan dan ramah, guna peningkatan kepuasan pasien.

Berdasarkan hasil penelitian tingkat dimensi empati (emphaty) semua atribut masuk ke dalam kuadran C (Prioritas Rendah) yaitu pernyataan no 12 yaitu memberikan perhatian secara khusus kepada setiap pasien, pernyataan no 13 Perhatian terhadap keluhan pasien dan keluarganya dan pernyataan no 14 Pelayanan kepada semua pasien tanpa memandang status sosial dan lain-lain.

Hasil penelitian Sri 2016 tentang tingkat kepuasan pasien terhadap pelayanan kesehatan di Puskesmas Baturetno, berdasarkan hasil analisis data pada dimensi empati hasil penghitungan tingkat kepuasan pada aspek empati, bobot rata-rata sebesar 831 dengan prosentase 72,89 yang menunjukkan bahwa responden merasa puas. Empati (emphaty) adalah kesediaan untuk peduli dan memberikan perhatian yang tulus dan bersifat pribadi kepada konsumen (pengguna jasa). Dimensi empati adalah dimensi yang memberikan peluang besar untuk menciptakan pelayanan yang surprise yaitu sesuatu yang tidak diharapkan pengguna jasa tetapi ternyata diberikan oleh penyedia jasa (2). Hasil penelitian ini diperkuat dengan pernyataan Imbalo bahwa empati merupakan salah satu dimensi mutu pelayanan yang dapat mengukur kepuasan pasien (16)

Menurut peneliti dimensi empati semua atribut masuk dalam Kuadran C. diharapkan kepada Kepala Puskemas untuk melakukan pembenahan terhadap sistem pelayanan di Puskesmas. Serta perlu adanya peningkatan dalam pelayanan sesusi dengan standar kebijakan pelayanan yang menampilkan senyum kepada pasien yang berkunjung dengan sikap $5 \mathrm{~S}$ yaitu Senyum, Sapa, Salam, Sopan dan Santun. Dengan adanya program tersebut memberikan dampak dampak pada perilaku petugas dalam memberikan pelayanan

Berdasarkan hasil penelitian tingkat dimensi bukti fisik yang masuk dalam kuadran B (Dipertahankan) adalah pernyataan no 15 Kebersihan, kerapian dan kenyamanan ruangan, pernyataan no 16 Penataaan eksterior dan ineterior ruangan dan pernyataan no 18 Kerapian dan kebersihan penampilan petugas. Kuadran C (Proritas Rendah) yaitu pada pernyataaan no 17 Kelengkapan, kesiapan dan kebersihan alat-alat yang dipakai.

Beberapa Hasil penelitian menunjukkan bahwa tangible merupakan faktor yang berhubungan dengan kepuasan pasien (17)(18). Hasil penelitian Cahyadi menunjukkan bukti fisik tidak berhubungan dnegan kepuasan pasien (19)

Hasil penelitian Herman 2019 tentang analisis faktor yang mempengaruhi mutu pelayanan kesehatan terhadap kepuasan pasien di puskesmas pasaman, berdasarkan hasil diperoleh nilai secara statistik dengan uji ChiSquare yaitu $p$ value $=0,0005$. Ini menunjukkan bahwa ada hubungan antara wujud fisik dengan kepuasan pasien. Bukti fisik atau bukti 
langsung merupakan ketersediaan sarana dan prasarana termasuk alat yang siap pakai serta penampilan karyawan atau staf yang menyenangkan. Timbulnya ketidak puasan pasien disebabkan karena wujud fisik yang ada tidak diiringi dengan daya tanggap yang baik dari petugas. Walaupun petugas kesehatan memiliki penampilan bersih dan rapi, tetapi dari segi waktu ia tidak datang tepat waktu, keadaan ruangan yang kurang fentilasi, jadi secara wujud fisik pandangan pasien terhadap petugas kesehatan menjadi kurang baik artinya petugas kesehatan tidak siap dalam melayani pasien dan kurangnya kenyamanan di dalam ruangan rawat inap (12).

Tangible merupakan salah satu bentuk dimensi mutu pelayanan dilihat dari fasilitas pelayanan kesehatan (20). Menurut peneliti dari dimensi bukti fisik yang masuk dalam Kuadran B, diharapkan atribut pelayanan ini untuk tetap dipertahankan dalam pelayanan di Puskesmas. Untuk mempertahankan atribut ini dapat dilakukan dengan cara melibatkan seluruh komponen yang ada (Tim Medis) melalui kerjasama Tim manajemen dibawah arahan Kepala Puskesmas untuk mengoptimalkan pelayanan kesehatan di Puskesmas. Pada kuadran C (Prioritas Rendah) pada pernyataan no 17 kelengkapan, kesiapan dan kebersihan alat-alat yang dipakai. Diharapkan kepada Kepala Puskesmas untuk melakukan evalusi setiap prosedur atau SOP ke setiap poli pelayanan dan koordinasi dari petugas baik perawat atau bidan menyiapakan kelengkapan alat pelayanan yang dibutuhkan. Agar proses pelayanan dapat berjalan dengan tepat dan cepat.

\section{KESIMPULAN DAN SARAN}

Tingkat kepuasan keseleruhan dengan tingkat kesesuainnya sebesar 95,09\%. Tingkat kepuasan responden dengan melihat tingkat kesesuaian antara harapan dan kenyataan pada dimensi kehandalan (reliability) sebesar 97,73\%, dimensi kehandalan daya tanggap (responsiveness) sebesar 95,75\%, dimensi jaminan (assurance) sebesar 95,06\%, dimensi empati (emphaty) sebesar 93,18\%, dimensi buti fisik (tangible) sebesar 95,94\%. Hasil analisa menggunakan diagram kartesius, faktor-faktor yang menjadi prioritas perbaikan (Kuadran A) dan harus dilaksanakan sesuai dengan harapan pelanggan adalah atribut pernyataan no 4 Prosedur Pelayanan tidak berbelit-belit dan pernyataan no 8 Pengetahuan dan kemampuan tenaga medis menetapkan diagnosis penyakit.

Disarankan kepada kepala Puskesmas Putri Ayu Kota Jambi untuk melakukan penigkatan dan evaluasi dalam program pelayanan sebagai berikut : a) Informasi alur pelayanan dan prosedur pelayanan dibuat dalam bentuk banner dengan tulisan yang informatif dan ditempatkan pada tempat yang mudah dibaca pengunjung Puskesmas; b) Memberikan pengarahan dan pengawasan serta koordinasi kepada petugas agar proses pelayanan di Puskesmas dapat dijalankan dengan cepat dan tepat; c) Mengadakan seminar dan evaluasi bagi para petugas puskesmas dalam hal pelayanan. agar dapat memberikan jaminan rasa aman dan nyaman bagi para pengguna pelayanan kesehatan

\section{DAFTAR PUSTAKA}

1. Rangkuti F. Measuring Customer Satisfaction. Jakarta: Gramedia Pustaka; 2006. 
2. Handayani S. Tingkat Kepuasan

Pasien Terhadap Pelayanan

Kesehatan di Puskesmas Batu

Retno. Media Publ Penelit

[Internet]. 2016;14(1):42-8.

Available from:

https://www.researchgate.net/public ation

3. Kuntoro W, Istiono W. Kepuasaan pasien terhadap kualitas pelayanan di tempat pendaftaran pasien rawat jalan Puskemas Kretek. J Kesehat Vokasional. 2017;2(1):140-7.

4. Ndambuki J. The Level of Patients Satisfaction and Perception On Quality of Nursing Service In The Renal Unit, Kenyatta National Hospital Nairobi, Kenya. J Med Heal Care. 2013;3(2).

5. A Latupono, Alimin M, Andi Z. Hubungan Mutu Pelayanan terhadap Kepuasan Pasien Rawat Inap di RSUD Masohi. JST Kesehat. 2015;5(1).

6. Sari. Hubungan Mutu Pelayanan Keperawatan dengan Tingkat Kepuasan Pasien di Ruang Rawat Inap RSUD dr. Rasidin Padang Tahun 2014. Universitas Andalas; 2014.

7. Dzomeku, V. M., Baetilayo., Atinga, P, Tuluku., Mantey RE. In patient satisfaction with nursing care : A case study at Kwame Nkrumah University of science and Technology Hospital. Int J Res Med Heal Sci. 2013;1(3):19-24.

8. Ardiansyah F. Analisis Faktorfaktor yang berhubungan dengan Kepuasan Pasien Peserta JKN tentang Pelayanan di Instansi Rawat Inap RSUD dr. M. Yunus Bengkulu. Universitas Andalas; 2015.

9. Faisal, Pangemanan, Engkeng. Hubungan antara Pelayanan Perawatan dengan Kepuasan Pasien di Instalasi Rawat Inap A Badan Layanan Umum Rumah Sakit Umum Pusat Prof. DR. Kandou
Kota Manado. J Kesehat Masy Univ Sam Ratulangi. 2013;1(6):24-38.

10. Ariyani. Hubungan Kualitas Pelayanan Dengan Loyalitas Pelnggan di Rumah Sakit Gigi dan Mulut Asri Medical Center Yogyakarta. Universitas Ahmad Dahlan; 2012.

11. Andriani S, Sunarto. Hubungan

Kualitas Pelayanan Kesehatan dengan Kepuasan Pasien Rawat Inap di Badan Pelayanan Kesehatan Rumah Sakit Umum Daerah Kabupaten Magelang. J Kesehat. 2010;2(1):70-80.

12. Herman, Sudirman, Nizmayanun. Hubungan Kualitas Pelayanan Kesehatan dengan Kepusan Pasien Rawat Jalan di Puskesmas Lembasada Kabupaten Donggala. Prev J Kesehat Masy. 2014;5(2):22-35.

13. Suryawati, Dharminto, Shalihiyah. Penyusunan Indikator Kepuasan Pasien Rawat Inap Ruah Sakit di Provinsi Jawa Tengah. J Manaj Pelayanan Kesehat. 2010;9(4):1782.

14. Abidin. Pengaruh Kualitas Pelayanan BPJS Kesehatan Terhadap Kepuasan Pasien di Puskesmas Cempae Kota Pare-Pare. J MKMI. 2016;12(2):70-5.

15. Hastuti SKW, Mudayana AA, Nurdhila AP, Hadiyatma D. Hubungan Mutu Pelayanan dengan Kepuasan Pasien Peserta BPJS di Rumah Sakit Umum Daerah Yogyakarta. Kes Mas J Fak Kesehat Masy. 2017;11(2):161-8.

16. Pohan I. Jaminan Mutu Pelayanan Kesehatan. Dasar-Dasar Pengertian dan Penerapan. Jakarta: EGC; 2007.

17. Nurrizka, Saputra. Pengukuran Indeks Kepuasan Masyarakat Terhadap Pelayanan Kesehatan. J Manaj Pelayanan Kesehat. 2011;14(1):9-11.

18. Siswati S. Kualitas Pelayanan Kesehatan dengan Kepuasan Pasien 
BPJS di Unit Rawat Inap. JMKMI. 2015;11(3):9-263.

19. Cahyadi, Mudayana. Hubungan Mutu Pelayanan dengan Kepuasa Pasien di Rumah sakit PKU

Muhammadiyah Yogyakarta Unit I.
Universitas Ahmad Dahlan; 2014.

20. Bustami. Penjaminan Mutu Pelayanan Kesehatan \& Akseptabilitasnya. Jakarta: Erlangga; 2011. 